ORIGINAL ARTICLE

\title{
Intravenous immunoglobulin for cystic fibrosis lung disease: a case series of 16 children
}

\author{
I M Balfour-Lynn, U Mohan, A Bush, M Rosenthal
}

Arch Dis Child 2004;89:315-319. doi: 10.1136/adc.2003.026575

See end of article for authors' affiliations

.....................

Correspondence to: I M Balfour-Lynn, Department of Paediatric Respiratory Medicine, Royal Brompton \& Harefield NHS Trust,

Sydney Street, London SW3 6NP, UK;

i.balfourlynn@ic.ac.uk

Accepted 3 June 2003
Background and objective: Some children with severe cystic fibrosis (CF) lung disease develop chest tightness, recurrent dry cough, and intractable wheeze, often accompanied by deteriorating lung function and failure to expectorate sputum. In an attempt to reduce the use of regular oral corticosteroids, we treated a group of such children with monthly courses of intravenous immunoglobulin (IVIG).

Methods: This is a retrospective case note review of 16 children, aged 3-16 years (median 13.0 years) who received 1-66 (median 7.5) courses of monthly IVIG, at a dose of $1 \mathrm{~g} / \mathrm{kg}$ on two successive days for the first dose, followed by $1 \mathrm{~g} / \mathrm{kg}$ monthly as a 12 hour infusion, with corticosteroid and antihistamine cover.

Results: $\mathrm{FEV}_{1}$ improved from a median ( $95 \%$ confidence interval $(\mathrm{CI})$ ) of $50 \%$ (39 to $61 \%$ ) to $54 \%$ (48 to $66 \%$ ), with a median $(95 \% \mathrm{Cl}$ ) difference of $+7.5 \%(-1.5$ to $14.5 \%$; NS). FVC improved from $65 \%$ (60 to $77 \%$ ) to $83 \%$ (70 to $89 \%$ ), with a difference of $+13 \%$ (4 to $22 \%, p=0.01)$. The total daily dose $/ \mathrm{kg}$ body weight of oral prednisolone was reduced from $0.6(0.3$ to 1.0$)$ to $0(0$ to 0.1$) \mathrm{mg} / \mathrm{kg} /$ day, with a reduction of $-0.6(-1.0$ to $-0.1, p=0.006) \mathrm{mg} / \mathrm{kg} /$ day. The total daily dose of inhaled corticosteroid (budesonide equivalent) was a median (range) of $2000 \mu \mathrm{g}(800-6000 \mu \mathrm{g})$, which was reduced to $1500 \mu \mathrm{g}(0-3200 \mu \mathrm{g})$. The median $(95 \% \mathrm{Cl})$ difference was $-400 \mu \mathrm{g}(-1600$ to $0 \mu \mathrm{g}), \mathrm{p}<0.05$. IVIG was well tolerated and the regimen acceptable to all but one of the children. The following transient adverse reactions were seen in only one patient each: headache, fever, hypotension, aseptic meningitis, and chest tightness.

Conclusion: We suggest that an $n=1$ trial of IVIG in carefully selected patients with severe obstructive CF lung disease is worth considering, as for some it may lead to significant benefit.
A small number of children with CF presents a particularly difficult challenge. Their clinical picture is characterised by chest tightness, recurrent dry cough, and intractable wheeze. They rarely produce sputum even though it is clearly trapped within their obstructed airways. Their lung function continues to deteriorate despite maximal therapy, which will usually have included dornase alfa, high dose inhaled corticosteroids (ICS) and long acting $\beta_{2}$ agonists. Oral corticosteroids are sometimes of benefit but chronic use leads to unacceptable side effects.

It is assumed that these children have severe small airways disease with distal air trapping, and bronchiectasis is not usually the predominant feature on their CT scan (fig 1). Whether they have co-existing asthma is debatable, but they are not necessarily atopic, and defining whether true asthma is also present in a child with CF is notoriously difficult. ${ }^{1}$ Some, but not all, of these children have allergic bronchopulmonary aspergillosis (ABPA) that tends to recur as soon as their oral corticosteroid dose is reduced.

We have previously reported a 12 year old boy who developed severe small airways obstruction that became resistant to medical treatment (which had included oral corticosteroids, methotrexate, and cyclosporin). ${ }^{2} \mathrm{He}$ then developed ABPA and became steroid dependent. On the basis of the initial encouraging report of the use of IVIG in severe asthma, ${ }^{3}$ he was started on monthly IVIG infusions. After 6 months, he was successfully weaned off oral steroids while maintaining his lung function. After this initial dramatic success, IVIG has been given to other children in a similar situation, as a steroid sparing agent, owing to concerns over the adverse effects associated with long term systemic corticosteroids. Sometimes it was given as an attempt to treat intractable symptoms that had not responded to oral steroids. We have reviewed our use of IVIG and present this case series in order to inform other CF centres of this therapeutic option.

\section{METHODS}

This is a retrospective case note review of all children with CF who have received IVIG since 1994, in a single tertiary paediatric CF centre with a clinic population of 350 children.

\section{Administration of IVIG}

Criteria for starting IVIG were significant symptoms of airway obstruction (for example intractable wheeze, tight chest, nonproductive cough), with a need for continuing oral corticosteroids or a poor response to corticosteroids. The intended IVIG course was six doses but the decision when to stop was made by one of the consultants on the basis of clinical response (or lack of it), and acceptability to the patients. Patients received IVIG at $1 \mathrm{~g} / \mathrm{kg}$ on two successive days for the first dose followed by $1 \mathrm{~g} / \mathrm{kg}$ monthly as a 12 hour infusion, usually given overnight. The children received cover with corticosteroid (intravenous hydrocortisone $4 \mathrm{mg} / \mathrm{kg}$ ) and antihistamine (intravenous chlorpheniramine 2-4 mg) prior to the infusion starting. Sandoglobulin ${ }^{\circledR}$ (Novartis, Frimley, UK) was used for the first 6 years in the clinic then Flebogamma ${ }^{\circledR}$ (Grifols UK Ltd, Cambridge, UK) after this. The change in product was caused by supply

Abbreviations: ABPA, allergic bronchopulmonary aspergillosis; $\mathrm{CF}$, cystic fibrosis; $\mathrm{FEV}_{1}$, forced expiratory volume in 1 second; FVC, forced vital capacity; ICS, inhaled corticosteroids; IVIG, intravenous immunoglobulin 


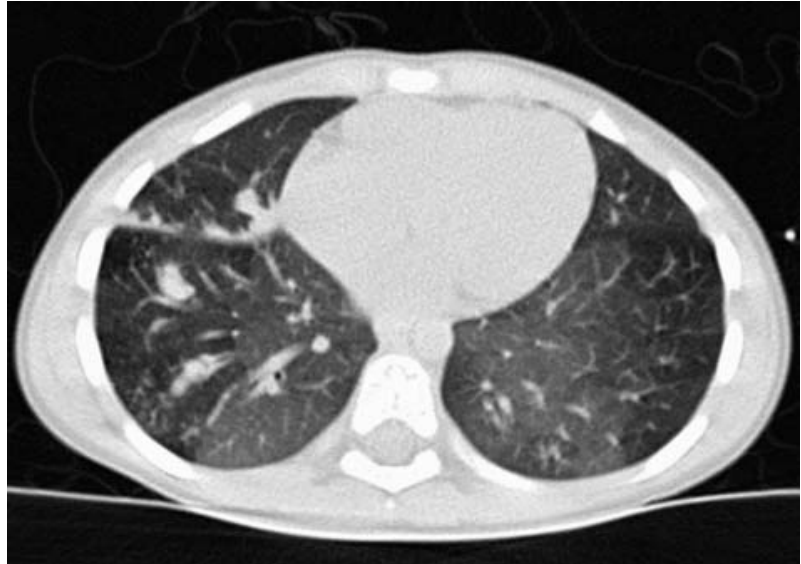

Figure 1 CT scan of patient 13 showing mucus plugging and air trapping but no frank bronchiectasis.

problems from Novartis. Both IVIG preparations are normal human immunoglobulin in the form of a polyvalent antibody preparation in $0.9 \%$ saline.

\section{Lung function}

$\mathrm{FEV}_{1}$ and forced vital capacity (FVC) were recorded as the percentage predicted for sex and height. Small airways function was not recorded owing to the inherent variability of such measurements.

\section{Assessment of therapeutic success}

An adequate response to treatment was defined as an improvement in reported symptoms (wheeze, chest tightness, cough), or a clinically significant improvement in lung function $\left(\mathrm{FEV}_{1}>10 \%\right)$, or a reduction in oral steroid dosage with no worsening in the above two parameters.

\section{Statistical analysis}

Statistical analysis was performed using Minitab software (Minitab Inc, State College, PA, USA). Non-parametric Wilcoxon tests were used to compare lung function $\left(\mathrm{FEV}_{1}\right.$ and FVC) and inhaled/oral corticosteroid total daily dose at the start and end of the courses of IVIG. Mann Whitney U tests were performed to compare differences in outcomes between different groups (high $v$ low serum IgE, ABPA $v$ nonABPA). Analysis was performed only on those patients who had received more than one dose of IVIG $(n=15)$. Values of $\mathrm{p}<0.05$ were considered statistically significant.

\section{RESULTS}

Since 1994, 16 children have been given 1-66 (median 7.5) courses of IVIG, with three children receiving it for more than 1 year (fig 2, table 1).

\section{Baseline characteristics}

There were nine girls and seven boys, aged 3-16 years (median 13.0 years). Eleven patients had chronic infection with Pseudomonas aeruginosa, while two were infected with Staphylococcus aureus. Ten patients had been diagnosed with ABPA in the past using the standard criteria, ${ }^{45}$ of whom six had active ABPA at the time of starting IVIG (determined by continued symptoms with a high total serum IgE and high aspergillus specific IgE). Treatment with oral corticosteroids (and oral itraconazole since 1998) was routinely given, but in many, symptoms recurred once corticosteroids were reduced. The child with the best lung function (patient 13; FEV 1 and FVC both $90 \%$ predicted) was a good example of this, and she

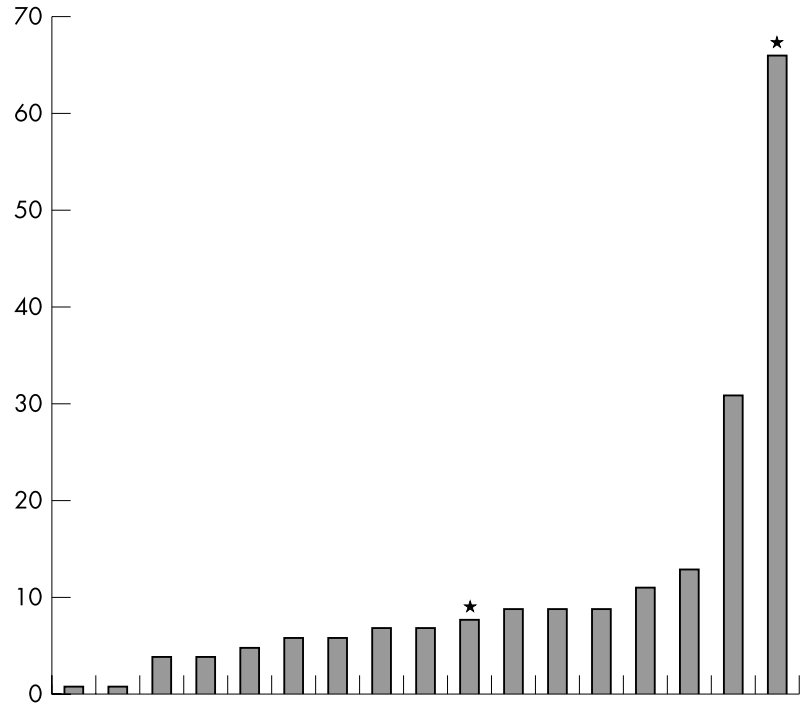

Figure 2 Number of courses of IVIG received.

also highlighted the lack of correlation between symptoms and lung function. Total serum $\operatorname{IgE}$ ranged from 7 to $8353 \mathrm{IU} / \mathrm{ml}$, with a median of $306 \mathrm{IU} / \mathrm{ml}$; five patients had levels $>500 \mathrm{IU} / \mathrm{ml}$. Serum IgG levels were normal in all but one patient who had levels just below the normal range for 2 years prior to starting IVIG (ranging from 3.2-4.9 g/l with normal age adjusted range of 5.4-16.1 g/l); the deficiency was presumed transient, as IgG levels normalised when she was older and had stopped IVIG therapy (IgA and IgM levels were normal). Prior to IVIG, baseline $\mathrm{FEV}_{1}$ ranged from 26 to $90 \%$ predicted (median $48 \%$ ), while FVC ranged from 33 to $90 \%$ predicted (median $65 \%$ ).

\section{Lung function}

Analysis of the single patient who received one dose only is excluded. $\mathrm{FEV}_{1}$ improved from a median (95\% confidence interval (CI)) of $50 \%$ (39 to $61 \%$ ) to $54 \%$ (48 to $66 \%$ ). The difference was $7.5 \%(-1.5$ to $14.5 \%$; NS) (fig 3$)$. FVC improved from $65 \%$ (60 to $77 \%$ ) to $83 \%$ (70 to $89 \%$ ), with a difference of $13 \%$ (4 to $22 \%$; $p=0.01$ ) (fig 3 ).

\section{Corticosteroids}

Twelve patients were on regular oral prednisolone, with a median daily dose of $32.5 \mathrm{mg}$ (range 2-60 mg). This represented a dose per $\mathrm{kg}$ body weight of $0.1-2.0 \mathrm{mg} / \mathrm{kg} /$ day (median 0.6). Oral corticosteroids were stopped completely in eight patients, reduced in three, and there was no change for one. One of the four patients who was not on oral steroids at the start, was receiving $0.5 \mathrm{mg} / \mathrm{kg} /$ day prednisolone when she died of invasive aspergillosis after her sixth dose of IVIG, ${ }^{6}$ while the other three remained off steroids. Taking the whole group, the median (95\% CI) total daily dose per $\mathrm{kg}$ was reduced from $0.6(0.3$ to 1.0$)$ to $0(0$ to 0.1$)$, with a median $(95 \%$ CI $)$ difference of $-0.6(-1.0$ to -0.1$) \mathrm{mg} / \mathrm{kg} / \mathrm{day}$, $\mathrm{p}=0.006$ (fig 4).

All patients were on regular twice daily inhaled corticosteroids (ICS). After IVIG, they were stopped completely in one, reduced in five and remained unchanged in nine patients. Total daily dose (budesonide equivalent) was median (range) of $2000 \mu \mathrm{g} \quad(800-6000 \mu \mathrm{g})$, which was reduced to median (range) of $1500 \mu \mathrm{g}(0-3200 \mu \mathrm{g})$. The median $(95 \% \mathrm{CI})$ difference was $-400 \mu \mathrm{g}(-1600$ to $0 \mu \mathrm{g})$, $\mathrm{p}<0.05$ (fig 4). 
Table 1 Patient characteristics

\begin{tabular}{|c|c|c|c|c|c|c|c|c|c|c|c|c|c|c|c|c|c|c|}
\hline \multirow{2}{*}{$\begin{array}{l}\text { Pat- } \\
\text { ient }\end{array}$} & \multirow{2}{*}{$\begin{array}{l}\text { Age } \\
\text { (years) }\end{array}$} & \multirow{2}{*}{ Genotype } & \multirow{2}{*}{$\begin{array}{l}\text { Serum } \\
\operatorname{lgE} \\
\text { (IU/ml) }\end{array}$} & \multirow{2}{*}{ PA } & \multirow[b]{2}{*}{ SA } & \multicolumn{2}{|l|}{ ABPA } & \multirow{2}{*}{$\begin{array}{l}\text { No. of } \\
\text { courses }\end{array}$} & \multicolumn{2}{|c|}{ FEV $_{1}(\%)$} & \multicolumn{2}{|c|}{ FVC (\%) } & \multicolumn{2}{|c|}{$\begin{array}{l}\text { Prednisolone } \\
\mathrm{mg} / \mathrm{kg} / \text { day }\end{array}$} & \multicolumn{2}{|c|}{ ICS $\mu \mathrm{g} /$ day } & \multirow{2}{*}{$\begin{array}{l}\text { Adverse } \\
\text { effects }\end{array}$} & \multirow[b]{2}{*}{ Comments } \\
\hline & & & & & & Past & Active & & Start & End & Start & End & Start & End & Start & End & & \\
\hline 1 & 13.8 & $\begin{array}{l}\Delta \mathrm{F} 508 / \\
\Delta \mathrm{F} 508\end{array}$ & 7 & $Y$ & $\mathrm{~N}$ & $N$ & $N$ & 31 & 36 & 62 & 65 & 85 & 0.20 & 0 & 800 & 800 & No & $\begin{array}{l}\text { Low lgG pre- } \\
\text { IVIG }\end{array}$ \\
\hline 2 & 15.4 & $\begin{array}{l}\Delta \mathrm{F} 508 / \\
\Delta \mathrm{F} 508\end{array}$ & 271 & Y & $Y$ & $\mathrm{~N}$ & $\mathrm{~N}$ & 9 & 48 & 69 & 60 & 84 & 1.20 & 0.20 & 1600 & 1600 & No & \\
\hline 3 & 12.7 & $\begin{array}{l}\Delta \mathrm{F} 508 / \\
621+\mid \mathrm{G}>\end{array}$ & 2424 & $\mathrm{~N}$ & $\mathrm{~N}$ & Y & Y & 9 & 40 & 51 & 78 & 87 & 0.60 & 0 & 2400 & 1600 & No & \\
\hline 4 & 9.0 & $\begin{array}{l}\Delta \mathrm{F} 508 / \\
\Delta \mathrm{F} 508\end{array}$ & 1326 & $\mathrm{~N}$ & $\mathrm{~N}$ & $Y$ & $Y$ & 4 & 70 & 70 & 81 & 87 & 0.80 & 0.80 & 3200 & 3200 & No & \\
\hline 5 & 11.4 & $\begin{array}{l}\Delta \mathrm{F} 508 / \\
\Delta \mathrm{F} 508\end{array}$ & 1739 & $\mathrm{~N}$ & $\mathrm{~N}$ & $Y$ & $Y$ & 7 & 29 & 38 & 33 & 52 & 1.20 & 0 & 3200 & 1600 & No & \\
\hline 6 & 16.6 & $\begin{array}{l}\Delta \mathrm{F} 508 / \\
1507\end{array}$ & 29 & $Y$ & $\mathrm{~N}$ & $N$ & $\mathrm{~N}$ & 11 & 26 & 27 & 61 & 68 & 1.00 & 0 & 3000 & 1500 & No & \\
\hline 7 & 14.6 & $\begin{array}{l}\Delta \mathrm{F} 508 / \\
\Delta \mathrm{F} 508\end{array}$ & 340 & $Y$ & $\mathrm{~N}$ & $Y$ & $\mathrm{~N}$ & 66 & 30 & 51 & 45 & 93 & 2.00 & 0 & 3200 & 0 & No & Index case \\
\hline 8 & 11.9 & $\begin{array}{l}\Delta \mathrm{F} 508 / \\
\Delta \mathrm{F} 508\end{array}$ & 424 & $\mathrm{~N}$ & $\mathrm{~N}$ & $Y$ & $N$ & 7 & 72 & 80 & 84 & 112 & 0 & 0 & 1000 & 1000 & No & \\
\hline 9 & 15.5 & $\begin{array}{l}\Delta \text { F508/ } \\
\text { G551D }\end{array}$ & 211 & $Y$ & $\mathrm{~N}$ & $N$ & $\mathrm{~N}$ & 1 & 36 & 31 & 40 & 56 & 0 & 0 & 1600 & 1600 & $\begin{array}{l}\text { Chest } \\
\text { tightness, } \\
\text { fever }\end{array}$ & $\begin{array}{l}\text { Refused } \\
\text { further dose. } \\
\text { Died post- } \\
\text { transplant }\end{array}$ \\
\hline 10 & 3.3 & $\Delta \mathrm{F} 508 / ?$ & 70 & Y & $\mathrm{N}$ & $\mathrm{N}$ & $\mathrm{N}$ & 6 & * & * & * & * & 1.50 & 0 & 1600 & 800 & $\begin{array}{l}\text { Aseptic } \\
\text { meningitis }\end{array}$ & $\begin{array}{l}\text { Marked } \\
\text { symptomatic } \\
\text { improvement } \\
\text { sustained }\end{array}$ \\
\hline 11 & 13.3 & $\begin{array}{l}\Delta \mathrm{F} 508 / \\
\Delta \mathrm{F} 508\end{array}$ & 27 & $\mathrm{~N}$ & Y & $\mathrm{N}$ & $\mathrm{N}$ & 6 & 47 & 55 & 59 & 62 & 0 & 0.20 & 1500 & 1500 & No & $\begin{array}{l}\text { Died of } \\
\text { invasive } \\
\text { aspergillosis } \\
\text { after 6th dose }\end{array}$ \\
\hline 12 & 13.4 & $\begin{array}{l}\Delta \mathrm{F} 508 / \\
\Delta \mathrm{F} 508\end{array}$ & 2993 & $Y$ & $\mathrm{~N}$ & $Y$ & $Y$ & 13 & 59 & 78 & 72 & 97 & 0.60 & 0 & 6000 & 1000 & No & \\
\hline 13 & 5.3 & $\begin{array}{l}\Delta F 508 / \\
G 542 X\end{array}$ & 8353 & Y & $\mathrm{N}$ & Y & $Y$ & 8 & 90 & 61 & 90 & 74 & 0.10 & 0 & 2000 & 2000 & $\begin{array}{l}\text { Headache, } \\
\text { hypotension }\end{array}$ & \\
\hline 14 & 13.6 & $\begin{array}{l}\Delta \mathrm{F} 508 / \\
\Delta \mathrm{F} 508\end{array}$ & 201 & Y & $\mathrm{N}$ & $Y$ & $\mathrm{~N}$ & 6 & 51 & 50 & 65 & 72 & 0.80 & 0.25 & 2000 & 2000 & No & \\
\hline 15 & 10.9 & $\begin{array}{l}\Delta \mathrm{F} 508 / \\
\Delta \mathrm{F} 508\end{array}$ & 84 & Y & $\mathrm{N}$ & $Y$ & $\mathrm{~N}$ & 5 & 51 & 45 & 64 & 65 & 0.30 & 0.15 & 800 & 800 & No & \\
\hline 16 & 8.5 & $\begin{array}{l}\Delta \mathrm{F} 508 / \\
\Delta \mathrm{F} 508\end{array}$ & 404 & Y & $\mathrm{N}$ & Y & Y & 9 & 56 & 52 & 88 & 82 & 0 & 0 & 800 & 800 & No & \\
\hline \multicolumn{3}{|c|}{ Median 13.0} & 306 & $Y=11$ & $Y=2$ & $Y=10$ & $Y=6$ & 7.5 & 48 & 52 & 65 & 82 & 0.6 & 0 & 1800 & 1500 & $\mathrm{No}=13$ & \\
\hline
\end{tabular}

\section{Effect of IgE and ABPA}

There were no significant differences in outcomes (change in $\mathrm{FEV}_{1}, \mathrm{FVC}$, oral or inhaled corticosteroid dose) between those with high serum IgE (>500 IU/ml) compared with low IgE $(<500 \mathrm{IU} / \mathrm{ml})$, nor between those with and without history of or current ABPA.

\section{Adverse reactions}

IVIG was well tolerated and the regimen acceptable to all but one of the children. The following adverse reactions were seen in one child each: headache, fever, hypotension, clinically diagnosed aseptic meningitis, and chest tightness. The child with chest tightness was sufficiently upset by her symptom that she refused further treatment with IVIG. Other recognised side effects of rashes, joint pains, and nausea were not seen. Since this review was completed, a further patient (a 16 year old girl) was started on IVIG, but 1 day after the first treatment was completed, she developed dilated pupils, severe headache, nausea, and vomiting that lasted 24-48 hours. This may have been a delayed aseptic meningitis or possibly caused by the formation of antigen-antibody complexes.

\section{DISCUSSION}

This series describes 16 children who received monthly infusions of IVIG in an attempt to control symptoms of severe CF lung disease and reduce their corticosteroid usage. In the index case, it has been so successful that he has continued on it for more than 7 years, and indeed his adult clinic has been unable to wean him off this therapy, as attempts to reduce the dose or increase the dose interval result in recurrence of his airways obstruction. For the majority of the children it was successful, with a reduction in oral corticosteroids in most and a reduction of ICS in some. This was achieved with lung function maintained and mostly improved. Overall, the regimen was well tolerated apart from in one child, who refused to carry on beyond her first dose. In some children, the improvement was maintained even after they had finished the course of treatment. This was particularly evident in the youngest child in the series, aged 3 years, whose severe recurrent wheezing illness seemed to be 'switched off' by six doses of IVIG.

The anti-inflammatory mechanisms of IVIG have been recently reviewed, ${ }^{7}$ but the mechanisms of action specific to $\mathrm{CF}$ are not known. Commercially prepared immunoglobulin consists primarily of intact IgG, with traces of IgA, soluble CD4, CD8, and HLA molecules, and certain cytokines. ${ }^{7}$ Owing to the presence of a broad range of protective antibodies in the IVIG, one mechanism may be a reduction in viral exacerbations; one child remarked that she had had no colds during the winter apart from when she missed a dose of IVIG. Interleukin-8 (IL-8), the potent neutrophil chemoattractant, is known to play a critical part in CF lung inflammation. In a small study of high dose IVIG given to two patients with severe asthma, it was shown that free IL-8 in peripheral blood was markedly reduced while IL-8/IgG complexes were increased. ${ }^{8}$ IVIG may contain autoantibodies 


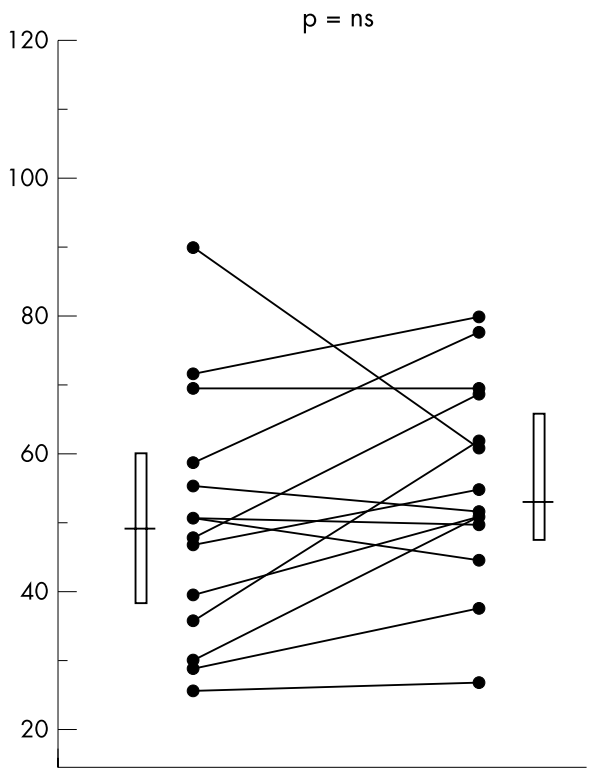

$\mathrm{FEV}_{1}(\%)$

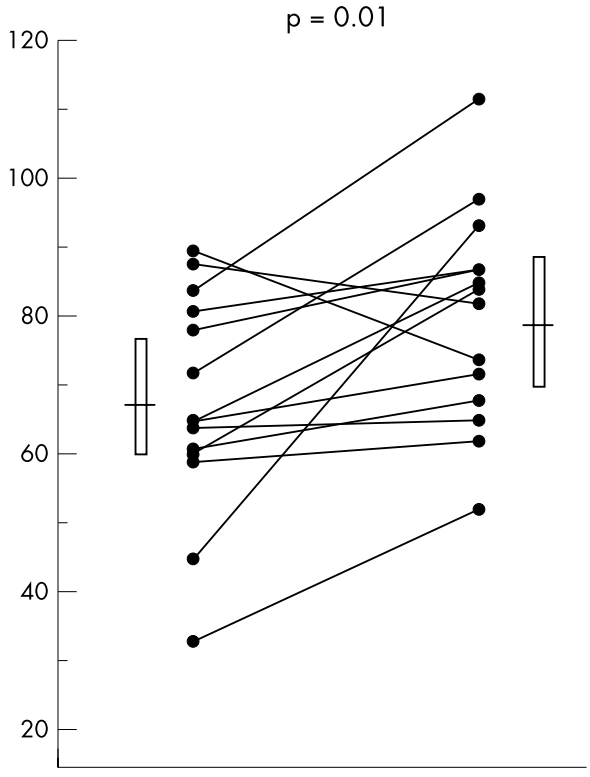

$\mathrm{FEV}_{1}(\%)$
Figure 3 Lung function $\left(\mathrm{FEV}_{1}\right.$ and FVC) before and after courses of IVIG. Also shown are medians (lines) and $95 \%$ confidence intervals (bars) against cytokines such as IL-8, which neutralise their biological effect, ${ }^{9}$ and binding of IL-8 to IgG would be likely to benefit patients with CF as well. There is some evidence that IVIG may modify the effect of $P$. aeruginosa. It has been suggested that it contains antibodies to Pseudomonas lipopolysaccharides and endotoxin. ${ }^{10}$ In theory, these antiPseudomonas antibodies may enhance killing of this organism and decrease immune complex formation, which has been implicated in lung destruction. In addition, in vitro work has shown that adding intact human IgG to CF alveolar macrophages leads to improved phagocytosis and intracellular killing of Pseudomonas. ${ }^{11}$ Pseudomonas specific hyperimmuneglobulin has been used as a form of passive immunotherapy in CF patients who were all chronically infected with $P$. aeruginosa. ${ }^{12}$ In an uncontrolled open study of 10 adults, a single dose was given during infective exacerbations. There was an improvement in lung function, an increase in anti- $P$. aeruginosa lipopolysaccharide IgG for eight immunotypes, an increase in serum anti- $P$. aeruginosa opsonic activity, and a decrease in sputum $P$ aeruginosa density.
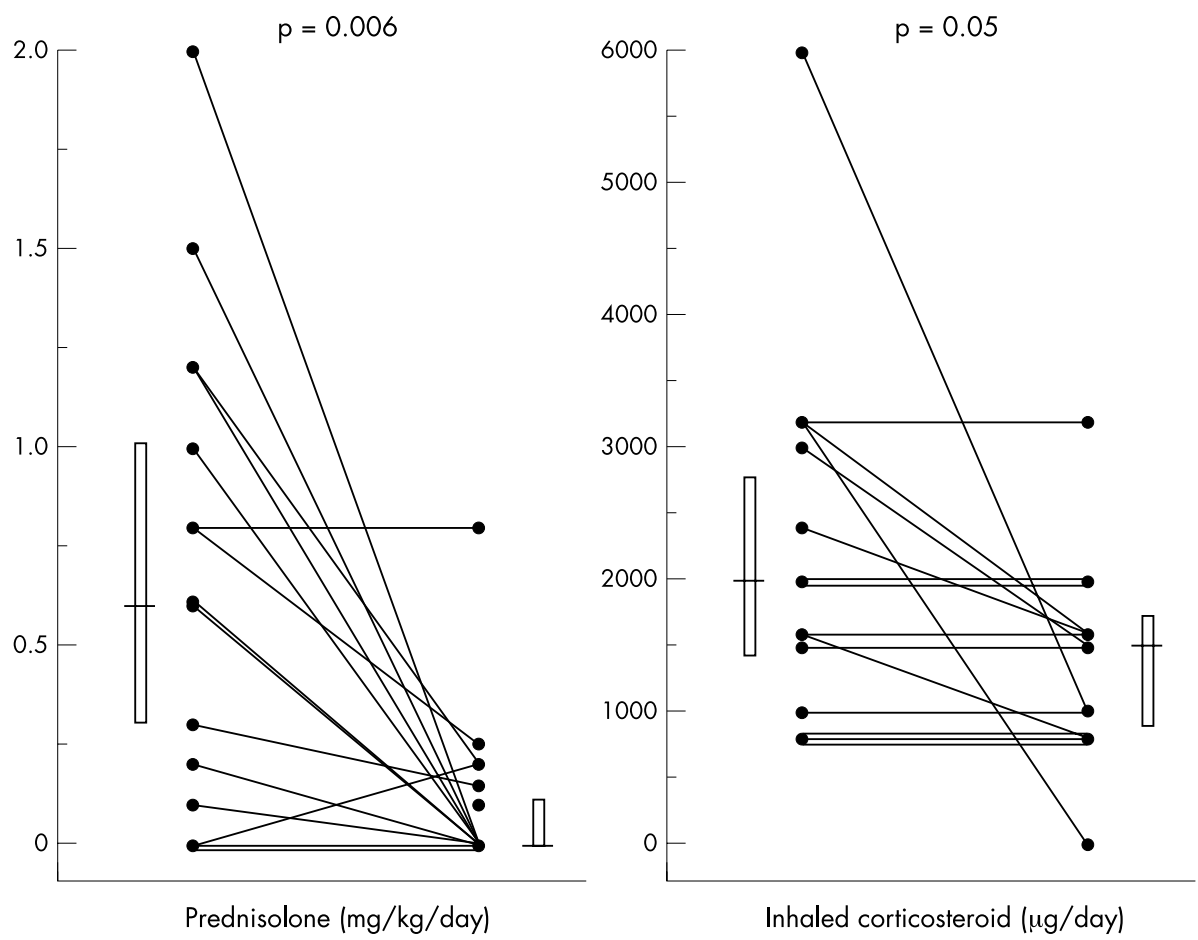

Figure 4 Oral prednisolone $(\mathrm{mg} / \mathrm{kg} /$ day) and inhaled corticosteroid ( $\mu \mathrm{g} /$ day budesonide equivalent) dosage before and after courses of IVIG. Also shown are medians (lines) and 95\% confidence intervals (bars). 
Finally, a double blind placebo controlled study examined the effect of low dose IVIG $(0.1 \mathrm{mg} / \mathrm{kg})$ infused on three successive days in $16 \mathrm{CF}$ patients undergoing intravenous antibiotic treatment for an infective exacerbation. ${ }^{10}$ The patients were aged over 12 years, had mild to moderate disease, and were all chronically infected with $P$. aeruginosa. There was a significant increase in lung function in the IVIG group (not sustained at 6 weeks) but no difference in either length of hospital stay, chest $x$ ray, or Shwachman scores.

Use of IVIG as an anti-inflammatory agent in CF began after initial reports of success in steroid dependent asthmatic patients. Three small open label studies found that IVIG infusions led to a reduction in oral steroid use in asthmatic children aged over 6 years. ${ }^{313}{ }^{14}$ Unfortunately, subsequent controlled trials were conflicting and failed to show conclusive benefit. ${ }^{15-17}$ One study of 31 child and adolescent asthmatics given four doses of $1 \mathrm{~g} / \mathrm{kg}$ over 8 weeks showed no benefit in lung function, bronchial hyper-reactivity, or symptom scores, although there was a trend to fewer days with upper respiratory tract infections. ${ }^{15}$ More encouragingly, a trial of 28 children and adults with asthma given a higher dose of $2 \mathrm{~g} / \mathrm{kg}$ at the start of treatment, followed by $400 \mathrm{mg} /$ kg every 3 weeks for 9 months, demonstrated a significant steroid sparing effect in the subgroup of patients who were taking high doses of oral steroids. ${ }^{16}$ Finally, another trial in asthmatics demonstrated no difference between two doses of immunoglobulin $(2 \mathrm{~g} / \mathrm{kg}$ and $1 \mathrm{~g} / \mathrm{kg})$ and placebo, given monthly for 7 months. ${ }^{17}$ This study also reported three cases of aseptic meningitis in the high dose treatment group, as well as rashes and hypertension. The mechanism of action in asthma is uncertain. However there is evidence of in vitro inhibition of IgE production by B cells, ${ }^{18}$ and that IVIG may act synergistically with dexamethasone to suppress lymphocyte proliferation. ${ }^{14}$ Following trials of therapy there have also been reports of improvement in glucocorticoid receptor binding affinity in peripheral blood mononuclear cells ${ }^{14}$ and a reduction in inflammatory cell influx into the airway mucosa. ${ }^{8}$ Some of these mechanisms could be applicable to the CF lung.

We have been unable to identify factors that determine which children will respond to this therapy, but that is not surprising given the small numbers. It did not relate to either serum IgE levels or the presence of active ABPA. Indeed, we are not suggesting IVIG as a new specific therapy for ABPA. In general, it was unusual to see a response (for example, to possibly start reducing the steroid dosage) before 3 months, and if there had been no benefit within 4-6 months we tended to stop the course. Inevitably, a degree of placebo effect cannot be excluded.

There are of course disadvantages to this form of therapy. The IVIG is not free of side effects, even though they were all transient; however, this is more than compensated for by the reduction in inevitable adverse effects of long term oral corticosteroids in CF. ${ }^{19}$ More significantly, IVIG is a blood product prepared from pooled plasma from 3000 to 10000 blood donors. Although there have been no reports of transmission of HIV, there were several outbreaks of hepatitis $\mathrm{C}$ in the mid-1990s. ${ }^{20}$ Indeed, the manufacturer's datasheet still states that the risk of hepatitis $\mathrm{C}$ cannot be entirely excluded. The situation over potential transmission of Creutzfeldt-Jakob disease is less clear, although UK derived plasma is not now used for the production of immunoglobulin in the UK. ${ }^{20}$ Repeated intravenous access is required, although many of these patients do already have an implanted venous access device. It is time consuming for the children and their carers, requiring a night in hospital every month. It is also expensive for the health services, both for the cost of IVIG and the hospital costs for an inpatient. Inevitably, it will be said by some that despite this encouraging case series, the use of IVIG in CF should await results of a proper randomised controlled trial or even a Cochrane systematic review. While we do not disagree with this worthy sentiment, realistically it is extremely unlikely that such a trial will ever happen. The patient group that would need to be studied is so diverse and (fortunately) scarce, that identification of a sufficient number of suitable patients to fit inclusion criteria would be impossible. Furthermore, the ethics of administering monthly intravenous placebo is highly questionable, especially in children such as these who are severely affected. Although there are other alternatives to steroids in this group of children, ${ }^{21}$ we would recommend that an $\mathrm{n}=1$ trial of IVIG in carefully selected patients with severe obstructive CF lung disease is worth considering, as for some it may lead to significant benefit.

\section{Authors' affiliations}

I M Balfour-Lynn, U Mohan, A Bush, M Rosenthal, Department of Paediatric Respiratory Medicine, Royal Brompton \& Harefield NHS Trust, Sydney Street, London, UK

Presented at the British Thoracic Society Winter Meeting 2000

\section{REFERENCES}

1 Balfour-Lynn IM, Elborn JS. CF asthma: what is it and what do we do about it? Thorax 2002;57:742-8.

2 Davies J, Rosenthal M, Bush A. Severe small airways disease resistant to medical treatment in a child with cystic fibrosis. J $R$ Soc Med 1996;89:172P-3P.

3 Mazer BD, Gelfand EW. An open-label study of high-dose intravenous immunoglobulin in severe childhood asthma. J Allergy Clin Immuno 1991;87:976-83.

4 Mastella G, Rainisio M, Harms HK, et al, on behalf of the investigators of the Epidemiologic Registry of Cystic Fibrosis. Allergic bronchopulmonary aspergillosis in cystic fibrosis. A European epidemiological study. Eur Resp J 2000;16:464-71.

5 Marchant JL, Warner JO, Bush A. Rise in total IgE as an indicator of allergic bronchopulmonary aspergillosis in cystic fibrosis. Thorax 1994;49:1002-5.

6 Brown K, Rosenthal M, Bush A. Fatal invasive aspergillosis in an adolescent with cystic fibrosis. Pediatr Pulmonol 1999;27:130-3.

7 Kazatchkine MD, Kaveri SV. Immunomodulation of autoimmune and inflammatory diseases with intravenous immune globulin. N Engl J Med 2001;345:747-55.

8 Vrugt B, Wilson S, van Velzen E, et al. Effects of high dose intravenous immunoglobulin in two severe corticosteroid insensitive asthmatic children. Thorax 1997; 52:662-4.

9 Sylvester I, Yoshimura T, Sticherling M, et al. Neutrophil attractant protein-1immunoglobulin $\mathrm{G}$ immune complexes and free anti-NAP-1 antibody in normal human serum. J Clin Invest 1992;90:471-81.

10 Winnie GB, Cowan RG, Wade NA. Intravenous immune globulin treatment of pulmonary exacerbations in cystic fibrosis. J Pediatr 1989;114:309-14.

11 Fick RB Jr, Naegel GP, Squier SU, et al. Proteins of the cystic fibrosis respiratory tract. Fragmented immunoglobulin $G$ opsonic antibody causing defective opsonophagocytosis. J Clin Invest 1984;74:236-48.

12 Van Wye JE, Collins MS, Baylor M, et al. Pseudomonas hyperimmune globulin passive immunotherapy for pulmonary exacerbations in cystic fibrosis. Pediatr Pulmonol 1990;9:7-18.

13 Jakobsson T, Croner S, Kjellman NI, et al. Slight steroid-sparing effect of intravenous immunoglobulin in children and adolescents with moderately severe bronchial asthma. Allergy 1994;49:413-20.

14 Spahn JD, Leung DYM, Chan MTS, et al. Mechanisms of glucocorticoid reduction in asthmatic subjects treated with intravenous immunoglobulin. J Allergy Clin Immunol 1999;103:421-6.

15 Niggemann B, Leupold W, Schuster A, et al. Prospective, double-blind, placebo-controlled, multicentre study on the effect of high-dose, intravenous immunoglobulin in children and adolescents with severe bronchial asthma. Clin Exp Allergy 1998;28:205-10.

16 Salmun LM, Barlan I, Wolf HM, et al. Effect of intravenous immunoglobulin on steroid consumption in patients with severe asthma: a double-blind, placebocontrolled, randomized trial. J Allergy Clin Immunol 1999;103:810-15.

17 Kishiyama JL, Valacer D, Cunningham-Rundles C, et al. A multicenter, randomised, double-blind, placebo-controlled trial of intravenous immunoglobulin for oral corticosteroid-dependent asthma. Clin Immunol 1999;91:126-33.

18 Sigman K, Ghibu F, Sommerville W, et al. Intravenous immunoglobulin inhibits IgE production in human B lymphocytes. J Allergy Clin Immunol 1998; 102:421-427.

19 Cheng K, Ashby D, Smyth R. Oral steroids for cystic fibrosis (Cochrane Review). In: The Cochrane Library, issue 1. Oxford: Update Software, 2002

20 Chapel HM. Safety and availability of immunoglobulin replacement therapy in relation to potentially transmissible agents. Clin Exp Immunol 1999; 1 18(Suppl 1):29-34.

21 Jaffé A, Balfour-Lynn IM. Treatment of severe small airways disease in children with cystic fibrosis: Alternatives to corticosteroids. Paediatr Drugs 2002;4:381-9. 